\title{
The current and future financial burden of hospital admissions for heart failure in Canada: a cost analysis
}

\author{
Dat T. Tran MPH, Arto Ohinmaa PhD, Nguyen X. Thanh MD PhD, Jonathan G. Howlett MD, \\ Justin A. Ezekowitz MBBCh MSc, Finlay A. McAlister PhD, Padma Kaul PhD
}

\section{Abstract}

Background: Heart failure is a costly health condition and a major public health concern. We sought to examine the costs of hospital admissions for heart failure between fiscal years 2004 and 2013 in Canada and to model the future costs to 2030.

Methods: Canadian Institutes for Health Information Discharge Abstract Database was used to identify admissions to hospital with heart failure as the primary diagnosis between fiscal years 2004 and 2013. Multiple linear regression models were used to calculate the trend in prevalence and extrapolate these to 2030. Canadian Institutes for Health Information patient cost estimates were used to identify costs of hospital admissions for heart failure. Generalized linear models were used to estimate average annual costs per heart failure patient. We conducted a sensitivity analysis including all admissions for heart failure in any diagnostic field.

Results: In 2013, 45600 (95\% confidence interval [Cl]: 43 800-47 200) patients were admitted with heart failure as the primary diagnosis, accounting for $\$ 482(95 \% \mathrm{Cl} \$ 464-\$ 500)$ million. By 2030, we estimate $54000(95 \% \mathrm{Cl} 49000-60000)$ patients and costs of $\$ 722$ (95\% Cl $\$ 650-\$ 801)$ million, with older adults (age $\geq 80 \mathrm{yr}$ ) accounting for $52 \%$ of costs. Including admissions for which heart failure was a secondary diagnosis increases the total cost to \$2.8 (95\% Cl \$2.6-\$3.0) billion in 2030.

Interpretation: As in other developed countries, hospital costs related to heart failure in Canada are on the rise. Older adults are the main consumers of such hospital services. Strategies to improve outpatient care to reduce rates of admission for heart failure are needed.

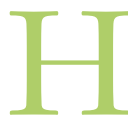
eart failure is a costly health condition and a major public health problem. It is estimated that $2 \%-3 \%$ of the population in developed countries has heart failure, and the prevalence increases to $8 \%$ among patients aged more than 75 years. ${ }^{1}$ Heart failure is the single most common reason for hospital admission. ${ }^{2,3}$ In the United States, it was projected that there would be 8.5 million people ( $3 \%$ of the US population) with heart failure in 2030, which would cost the US health system $\$ 53$ billion. ${ }^{4}$

It has been hypothesized that a combination of improved survival in heart failure patients $s^{5-7}$ and population aging $^{8}$ is expected to increase the burden of this condition in Canada. However, little is known as to the current and future financial burden of heart failure on the Canadian health care system.

The objectives of our study were to examine hospital admission costs for heart failure between fiscal years 2004 and 2013 in Canada and, based on these costs, model the future prevalence and admission costs to 2030. Although long-term heart failure prevalence and costs in Canada may change as a result of new therapies or changes in management strategies, forecasts based on current trends can serve as useful benchmarks to examine the effects of future innovations on health care costs.

\section{Methods}

\section{Annual volume of patients from 2004 to 2013 (all of Canada except Quebec)}

The Canadian Institute for Health Information Hospital Discharge Abstract Database from 2004 to 2013 for all Canadian provinces and territories except Quebec was used to identify hospital admissions with a primary diagnosis of heart failure (International Statistical Classification of Diseases and Related Health Problems, 10th revision, code I50).

Canadian population estimates for the same period from Statistics Canada (minus Quebec) were used as denominators to calculate annual prevalence rates per 100000 population by sex and age (<60 yr, 60-69 yr, 70-79 yr and $\geq 80 \mathrm{yr}$ ). Patients with multiple admissions for heart failure during the same year were counted once.

\section{Competing interests: None declared.}

This article has been peer reviewed.

Correspondence to: Padma Kaul, pkaul@ualberta.ca

CMAJ Open 2016. DOI:10.9778/cmajo.20150130 


\section{Estimating national volume of heart failure patients from 2004 to 2013 (including Quebec)}

We did not have data on admissions for heart failure for the province of Quebec. To calculate national estimates for the burden of heart failure, we assumed the prevalence rates of hospital admission for heart failure in Quebec to be the average across all other provinces and territories and used multiple linear regression (natural logarithm of prevalence rate as the dependent variable) with fiscal year, sex, age group and the interaction between sex and age as independent variables in the model. Joinpoint regression was used ${ }^{5,10-12}$ to detect significant changes in annual prevalence rates between 2004 and 2013. We recorded significant turning points at an $\alpha$ level of 0.05 to use as a knot in the multiple linear regression model. Model assumptions (homoscedasticity, normality of residuals, and the linearity of relationships between the outcome and fiscal year as a continuous predictor) were checked and explored for unusual and influential observations by examining residuals and leverage values. The number of patients was derived by multiplying the estimated prevalence rate from the multiple linear regression model with the Canadian population (including Quebec) for each age and sex group for each year.

\section{Annual hospital costs per heart failure patient from 2004 to 2013}

The cost of each admission to hospital was obtained from the Canadian Institute for Health Information, where the patient cost estimates were made using an algorithm that took case mix groups, resource intensity weight, cost per weighted case and length of stay into consideration. This calculation provides average costs incurred through the direct care of hospital inpatients (e.g., inpatient nursing, diagnostic and therapeutic costs). ${ }^{13,14}$ For case mix groups that did not have cost available in the Canadian Institute for Health Information data, we used the Ontario Case Costing Initiative ${ }^{15}$ instead. All costs were converted to 2014 dollars using the Bank of Canada inflation calculator. ${ }^{16}$ Annual inpatient costs for a heart failure patient were derived by summing costs of all hospital admissions of that patient in a year. We fitted a generalized linear model with gamma distribution and $\log$ link to estimate average annual admission costs per patient for the entire study period (2004-2013). The variables included in the model were fiscal year, patient sex and age group. Other patient factors were not included because they were already incorporated into the Canadian Institute for Health Information patient cost estimate algorithm.

The annual total hospital admission costs associated with heart failure in Canada from 2004 to 2013 were derived by multiplying the estimated number of patients admitted with the annual hospital cost per patient.

\section{Projection of heart failure prevalence and costs from 2014 to 2030}

We assumed that the trend seen during 2004 to 2013 would continue. The coefficients from the multiple linear regression and generalized linear models described earlier were used to predict the expected prevalence rate and admission cost per heart failure patient for each year from 2014 to 2030. We used Canadian population estimates (medium population growth - M5) from 2014 to $2030^{8,17}$ to calculate the expected number of heart failure patients for each year. The annual total admission costs for 2014-2030 were then derived by multiplying the expected number of admitted patients with the annual admission cost per patient.

\section{Sensitivity analyses}

We conducted 3 sensitivity analyses. First, we examined the uncertainty around our annual cost estimates by varying the estimated average annual admission cost per patient within its 95\% confidence interval (CI). Second, we added low and high population growth scenarios ${ }^{8,17}$ into projections of prevalence and costs from 2014 to 2030. Finally, we recalculated prevalence and cost estimates based on admissions for which heart failure was coded as either a primary or secondary diagnosis. Our primary analysis is based on admission for which heart failure was coded as the primary diagnosis. However, heart failure has been shown to be associated with other conditions, such as acute coronary syndromes and renal disease. It is therefore possible that when heart frailure is present as a secondary diagnosis, it could contribute to hospital costs.

\section{Results}

\section{Characteristics of the study population (all provinces except Quebec)}

Between 2004 and 2013, there were 421121 hospital admissions with a primary diagnosis of heart failure in Canada, excluding Quebec (Table 1). The mean expected length of stay for an admission increased from 7.5 days in 2004 to 8.3 days in 2013. However, the median acute length of stay remained stable at 6 days. The number of admissions and patients both reached the lowest point in 2007 and then increased. Female patients outnumbered male patients in the first 3 years. Patient mean age increased over time, as did the proportion of patients over the age of 80 years. Diabetes, chronic obstructive pulmonary and renal diseases were the most common comorbidities among heart failure patients. The largest increase in comorbidity rate was for diabetes, which increased from $29.3 \%$ in 2004 to $45.7 \%$ in 2013. Proportion of patients with more than 1 admission with heart failure as the primary diagnosis per year increased from $17.9 \%$ in 2004 to $18.8 \%$ in 2013 .

\section{National volume of heart failure patients from 2004 to 2013 (including Quebec)}

The results of the multiple linear regression model to estimate the prevalence rate of heart failure hospital admissions over time for each age and sex group are shown in Appendix 1 (available at www.cmajopen.ca/content/4/3/E365/suppl/DC1). These rates declined over time in all groups (Figure 1). The prevalence rates were more than 100 times higher in the oldest compared with the youngest groups in both sexes. Hospital admissions for heart failure were more prevalent in men in all age groups.

In contrast to the declining trend in hospital admission prevalence rates, the absolute number of heart failure patients 


\begin{tabular}{|c|c|c|c|c|c|c|c|c|c|c|}
\hline Characteristic & 2004 & 2005 & 2006 & 2007 & 2008 & 2009 & 2010 & 2011 & 2012 & 2013 \\
\hline $\begin{array}{l}\text { Admissions to } \\
\text { hospital, no. }\end{array}$ & 43102 & 42039 & 41033 & 40390 & 40899 & 41084 & 41585 & 42298 & 43163 & 45528 \\
\hline $\begin{array}{l}\text { Mean ELOS*, d } \\
\text { (SD) }\end{array}$ & $\begin{array}{c}7.5 \\
(4.1)\end{array}$ & $\begin{array}{c}7.5 \\
(4.1)\end{array}$ & $\begin{array}{c}7.7 \\
(4.4)\end{array}$ & $\begin{array}{c}7.8 \\
(4.7)\end{array}$ & $\begin{array}{c}7.9 \\
(4.8)\end{array}$ & $\begin{array}{c}8.0 \\
(5.0)\end{array}$ & $\begin{array}{c}8.1 \\
(5.1)\end{array}$ & $\begin{array}{c}8.3 \\
(5.1)\end{array}$ & $\begin{array}{c}8.4 \\
(5.3)\end{array}$ & $\begin{array}{l}8.3 \\
(5.3)\end{array}$ \\
\hline Median aLOS (IQR) & $\begin{array}{c}6 \\
(3-11)\end{array}$ & $\begin{array}{c}6 \\
(3-11)\end{array}$ & $\begin{array}{c}6 \\
(3-11)\end{array}$ & $\begin{array}{c}6 \\
(3-11)\end{array}$ & $\begin{array}{c}6 \\
(3-11)\end{array}$ & $\begin{array}{c}6 \\
(3-11)\end{array}$ & $\begin{array}{c}6 \\
(3-11)\end{array}$ & $\begin{array}{c}6 \\
(3-11)\end{array}$ & $\begin{array}{c}6 \\
(3-11)\end{array}$ & $\begin{array}{c}6 \\
(3-11)\end{array}$ \\
\hline Patients & 34311 & 33600 & 32876 & 32542 & 33004 & 32995 & 33144 & 33753 & 34365 & 36142 \\
\hline Male/female ratio & 0.96 & 0.98 & 0.98 & 1.00 & 1.02 & 1.01 & 1.01 & 1.01 & 1.03 & 1.04 \\
\hline Mean age, yr (SD) & $\begin{array}{c}76.8 \\
(12.1)\end{array}$ & $\begin{array}{l}76.9 \\
(12.4)\end{array}$ & $\begin{array}{c}77.1 \\
(12.3)\end{array}$ & $\begin{array}{c}77.1 \\
(12.5)\end{array}$ & $\begin{array}{c}77.2 \\
(12.5)\end{array}$ & $\begin{array}{c}77.1 \\
(12.7)\end{array}$ & $\begin{array}{c}77.6 \\
(12.4)\end{array}$ & $\begin{array}{c}77.6 \\
(12.5)\end{array}$ & $\begin{array}{c}77.8 \\
(12.6)\end{array}$ & $\begin{array}{c}77.9 \\
(12.7)\end{array}$ \\
\hline \multicolumn{11}{|c|}{ Patient proportion by age group, yr, \%† } \\
\hline$<60$ & 8.8 & 9.2 & 8.8 & 9.0 & 9.2 & 9.0 & 8.4 & 8.6 & 8.5 & 8.6 \\
\hline $60-69$ & 13.5 & 13.7 & 13.5 & 13.8 & 13.7 & 14.5 & 14.0 & 13.8 & 13.7 & 14.0 \\
\hline $70-79$ & 29.8 & 28.7 & 27.8 & 27.1 & 27.0 & 26.2 & 25.7 & 25.1 & 24.6 & 23.8 \\
\hline$\geq 80$ & 47.8 & 48.4 & 50.0 & 50.1 & 50.2 & 50.3 & 51.9 & 52.5 & 53.2 & 53.6 \\
\hline \multicolumn{11}{|l|}{ Patient comorbidity, \% } \\
\hline AMI & 11.7 & 11.7 & 12.0 & 11.9 & 12.7 & 11.6 & 11.6 & 11.1 & 10.5 & 9.6 \\
\hline COPD & 19.5 & 19.4 & 20.1 & 19.7 & 20.5 & 20.2 & 21.0 & 21.1 & 20.7 & 20.2 \\
\hline Dementia & 5.2 & 5.1 & 5.4 & 5.2 & 5.5 & 5.3 & 5.9 & 6.0 & 5.9 & 5.9 \\
\hline Diabetes & 29.3 & 30.4 & 40.0 & 40.9 & 40.6 & 45.0 & 44.7 & 44.9 & 45.5 & 45.7 \\
\hline Renal & 19.0 & 20.0 & 18.6 & 18.0 & 18.8 & 14.6 & 14.4 & 14.2 & 13.9 & 14.3 \\
\hline $\begin{array}{l}\text { Patients with > } 1 \\
\text { admission, \% }\end{array}$ & 17.9 & 17.7 & 17.8 & 17.4 & 17.4 & 17.6 & 18.2 & 18.4 & 18.6 & 18.8 \\
\hline $\begin{array}{l}\text { Note: aLOS = acute length } \\
\text { range, SD = standard devia } \\
{ }^{*} \text { Number of days in hospita } \\
\text { †Total percentage may not }\end{array}$ & $\begin{array}{l}\text { AMI }=a \\
\text { ed to ea } \\
\text { tly } 100 \%\end{array}$ & $\begin{array}{l}\text { myocardia } \\
\text { dmission } \\
\text { ause of } r c\end{array}$ & $\begin{array}{l}\text { arction, } \mathrm{C} \\
\text { en on } \mathrm{ClH} \\
\text { ling }\end{array}$ & $\begin{array}{l}=\text { chronic } \\
\text { uping meth }\end{array}$ & $\begin{array}{l}\text { tructive } p \\
\text { logy. }\end{array}$ & ary di & & ted I & stay, IC & terquartile \\
\hline
\end{tabular}

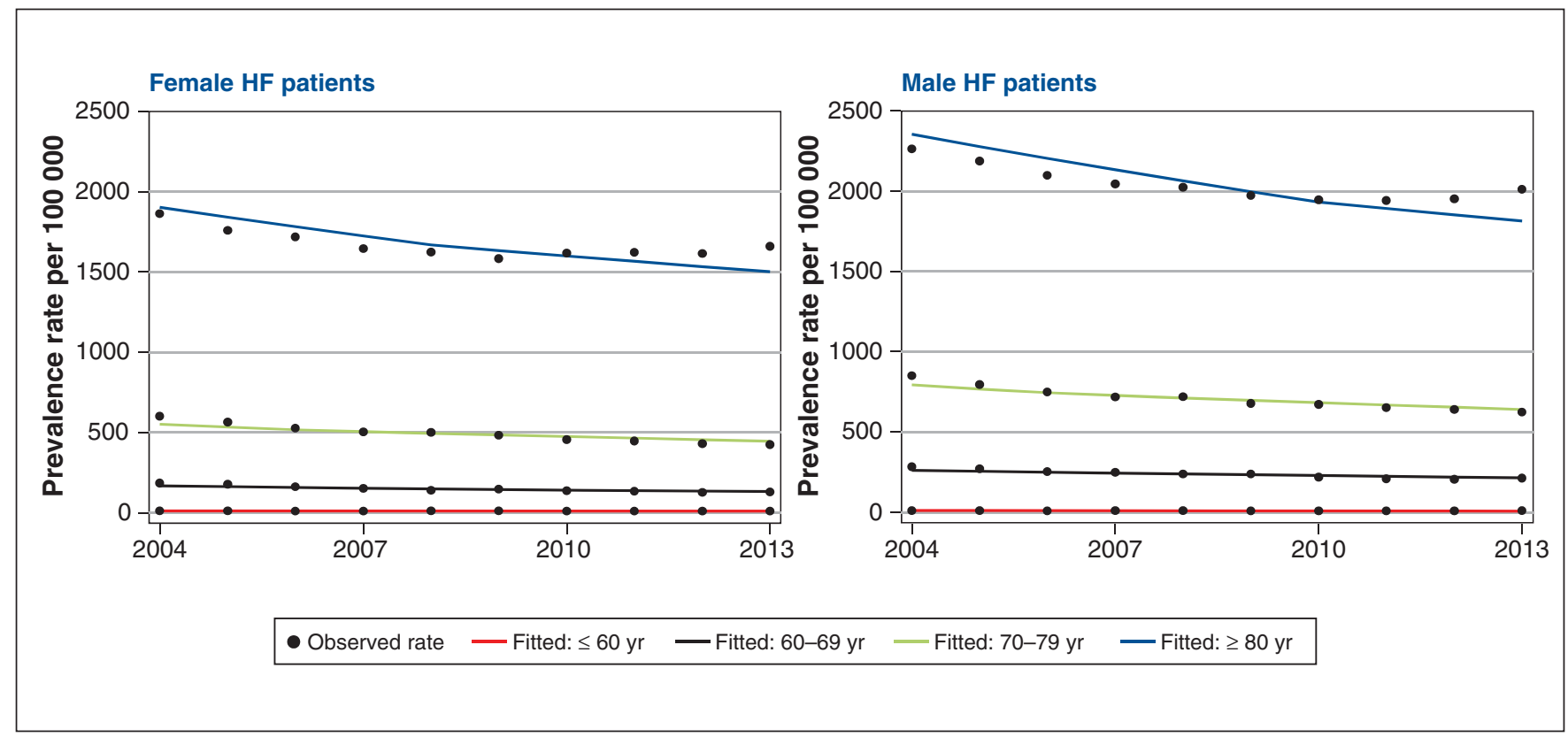

Figure 1: Prevalence rates of hospital admissions for heart failure (HF) in Canada, 2004-2013. 
admitted to hospital increased over time. There were 34311 patients admitted with heart failure in 2004, and this number increased to 36142 in 2013 (Table 1). Extrapolating to include Quebec, we estimated 44400 (95\% CI 42 500$46300)$ patients were admitted in 2004, and 45600 (95\% CI 43 800-47 200) in 2013, with a primary diagnosis of heart failure.

\section{Annual admission costs per patient from 2004 to 2013}

Results of the generalized linear model estimating annual admission cost per heart failure patient are presented in Appendix 1. Admission costs increased by $1.4 \%$ annually and were higher for men and younger patients. The average per patient costs in 2004 and 2013 were estimated at $\$ 9700$ and $\$ 11000$, respectively (Table 2).

Total admission costs from 2004 to 2013 increased gradually (Figure 2). Using 2014 dollar values, the total cost was \$415 (95\% CI \$397-\$432) million in 2004 and \$482 (95\% CI \$464-\$500) million in 2013, equivalent to a $1.7 \%$ annual increase during this period. In 2013, older adults (age $\geq 80 \mathrm{yr}$ ) accounted for $48.1 \%$ of costs; patients aged 70-79 years, $60-69$ years and less than 60 years accounted for $27 \%, 16.2 \%$ and $8.7 \%$ of costs, respectively.

\section{Projection of prevalence and costs from 2014 to 2030}

Results of cost projection to 2030 are presented in Appendix 2 (available at www.cmajopen.ca/content/4/3/E365/suppl/DC1). We estimated about 48000 (95\% CI 45 000-51 000) patients in 2020 and about 54000 patients (95\% CI 49 000-60 000 patients) in 2030. Annual admission costs per patient were projected to increase to about $\$ 12000$ in 2020 and about $\$ 14000$ in 2030. Total admission costs were projected to increase to $\$ 722$ (95\% CI \$650-\$801) million in 2030 (Figure 2). This reflects a $49.8 \%$ increase from 2013 to 2030. The older adults (age $\geq 80 \mathrm{yr}$ ) were projected to account for $52 \%$ of total costs in 2030 .

\section{Sensitivity analyses}

Varying annual admission cost per patient within its 95\% CI led to a maximum deviation of $1 \%$ of total costs in 2013 . The deviation increased to $5.8 \%$ in 2030 . This translated to a range of total admission costs from $\$ 477$ to $\$ 487$ million and from $\$ 681$ to $\$ 764$ million in 2013 and 2030, respectively.

Compared with medium population growth, low population growth resulted in 1500 fewer projected heart failure patients and high population growth resulted in an additional 2500 projected patients in 2030. Consequently, the low population growth scenario would be associated with a \$22 million reduction and the high population growth scenario would be associated with an additional $\$ 33$ million in admission costs.

Results of prevalence and cost estimates based on admissions with heart failure as either the primary or secondary diagnosis are provided in Appendix 3 (available at www.cmajopen .ca/content/4/3/E365/suppl/DC1). Extending the analyses to include admissions with heart failure as a secondary diagnosis more than tripled ( $n=175201$ [95\% CI 164 185-186 838]) the estimate of patients admitted to hospital with heart failure in 2030. Consequently, total costs associated with heart failure were projected to be $\$ 2.82$ (95\% CI \$2.65-\$3.01) billion in 2030 .

\section{Interpretation}

Patients who were admitted to hospital with a primary diagnosis of heart failure cost the Canadian health care system $\$ 415$ million in 2004 and $\$ 482$ million in 2013. These admissions therefore accounted for $0.8 \%$ of hospital spending in $2013 .{ }^{18}$ We estimate that the cost of admissions with heart failure as the primary diagnosis will increase substantially by 2030 to about $\$ 720$ million (50\% increase from 2013), assuming the current patterns continue. Older adults (age $\geq 80 \mathrm{yr}$ ) are the largest consumers of hospital services associated with heart failure. Including admissions where heart fail-

\begin{tabular}{|lcccc|}
\hline \multicolumn{5}{|l|}{$\begin{array}{l}\text { Table 2: Annual hospital admission cost for patients admitted to } \\
\text { hospital for heart failure (in 2014 dollar values) }\end{array}$} \\
\hline Characteristic & 2004 & 2007 & 2010 & 2013 \\
\hline Mean cost per patient, \$ & 9679 & 10092 & 10522 & 10970 \\
\hline Women, yr & & & \\
\hline All ages & 9543 & 9950 & 10374 & 10816 \\
\hline$<60$ & 10044 & 10472 & 10918 & 11383 \\
\hline $60-69$ & 9917 & 10339 & 10780 & 11239 \\
\hline $70-79$ & 9498 & 9903 & 10325 & 10765 \\
\hline$\geq 80$ & 8714 & 9085 & 9472 & 9876 \\
\hline Men, yr & & & \\
\hline All ages & 9816 & 10234 & 10670 & 11125 \\
\hline$<60$ & 10331 & 10771 & 11230 & 11709 \\
\hline $60-69$ & 10200 & 10635 & 11088 & 11560 \\
\hline $70-79$ & 9770 & 10186 & 10620 & 11073 \\
\hline$\geq 80$ & 8963 & 9345 & 9743 & 10158 \\
\hline
\end{tabular}


ure is a secondary diagnosis increased the cost estimate to $\$ 2.8$ billion by 2030 .

Inpatient prevalence rates are declining in both sexes. This might be due to improved management of heart failure in outpatient clinics. ${ }^{19}$ However, the absolute number of patients admitted to hospital is increasing. This is largely due to the change in population demographics. Statistics Canada has projected marked increases in the oldest age groups where heart failure is most prevalent: the proportion of people aged 80 years and over is expected to increase by $73 \%$ in the next 15 years, from 1.1 million people ( $4.1 \%$ of total population) in 2015 to 1.9 million (6.1\% of total population) in $2030 .{ }^{8}$ Our estimate of the increasing trend in the absolute number of heart failure patients admitted to hospital is more conservative than that reported previously. ${ }^{20}$ This is probably because we focused on hospital admission with a primary diagnosis of heart failure. Extending the analysis to include admissions where heart failure was coded as a secondary diagnosis more than tripled our estimates of the number of patients admitted.

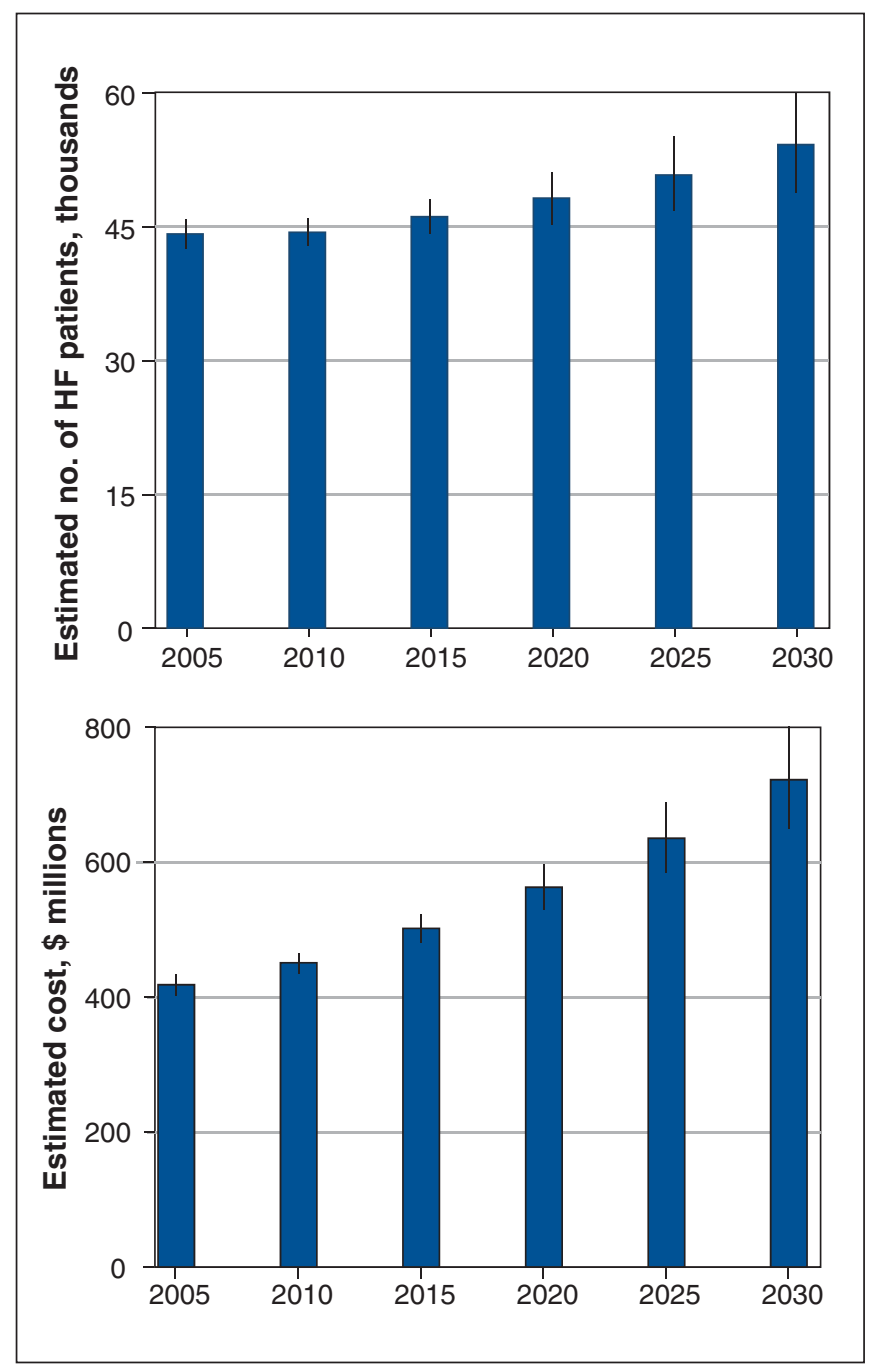

Figure 2: Estimated admission costs for heart failure and number of heart failure patients, 2004-2013, and projected for 2014-2030 (in 2014 \$ values). Error bars incidate 95\% confidence intervals.
Furthermore, we used more recent data (of 10 consecutive years up to 2013) and thus were able to take into account the slightly decreasing trends in admission prevalence in all age groups, whereas the previous study by Johansen and colleagues used only a single data point of fiscal year 1996/97. ${ }^{20}$

We projected that a patient admitted to hospital with a primary diagnosis of heart failure would cost the health care system about $\$ 14000$ per year in 2030. This is higher than the average cost of $\$ 8200$ in the United States (converted to 2014 Canadian dollars assuming admission accounts for $80 \%$ of medical costs ${ }^{4}$ and $80 \%$ of patients with heart failure are admitted $\left.^{21}\right)$. This could be explained by our use of case mix groups, which take comorbidities into consideration, whereas the US study modelled medical costs attributable to heart failure only. Furthermore, patterns of care may also account for the difference in cost estimates between the 2 countries. We have previously shown that heart failure patients in Canada have lengths of stay that are longer than their US counterparts. ${ }^{22}$

\section{Limitations}

We assumed that the trend in hospital admission patterns seen during 2004 to 2013 would continue. Long-term heart failure prevalence and costs in Canada may change as a result of new therapies or changes in management strategies. It should be noted that the continuous widening of $95 \%$ CIs of the estimates (Figure 2) suggests increased uncertainty over time.

We did not have hospital admissions data from Quebec and assumed prevalence rates in that province to be the mean across all other provinces and territories. However, we examined variation across provinces and found no statistically significant difference in prevalence rates between provinces where we have data. This result strengthened our assumption.

Finally, this study only included hospital costs and does not include other costs, such as physician, outpatient and drug costs, which are of increasing importance as the management of heart failure shifts from the inpatient to the outpatient setting. ${ }^{19}$ However, about $80 \%$ of total medical costs associated with heart failure can be attributed to hospital costs. ${ }^{4,23}$

\section{Conclusion}

As with other developed countries, the hospital resources related to the care of heart failure patients in Canada are increasing. Hospital admissions for which heart failure is the primary diagnosis cost the country $\$ 482$ million in 2013 , and these costs are projected to increase to $\$ 720$ million by 2030 . Including costs where heart failure is the secondary diagnosis increased the total cost in our estimates to a sobering $\$ 2.8$ billion by 2030 . Older adults are the main consumers of hospital services associated with heart failure. Strategies to improve outpatient care to reduce admission rates are needed, as are innovations that provide seamless, cost-effective and evidence-based interventions from the emergency department through to discharge. Although long-term projection is subject to assumptions and uncertainties, we believe that our study offers a reasonable indication of future resource needs for heart failure in inpatient settings from today's perspective. 


\section{References}

1. Bui AL, Horwich TB, Fonarow GC. Epidemiology and risk profile of heart failure. Nat Rev Cardiol 2011;8:30-41.

2. Neumann T, Biermann J, Erbel R, et al. Heart failure: the commonest reason for hospital admission in Germany: medical and economic perspectives. Dtsch Arztebl Int 2009;106:269-75.

3. Ross H, Howlett J, Arnold JM, et al. Treating the right patient at the right time: access to heart failure care. Can 7 Cardiol 2006;22:749-54.

4. Heidenreich PA, Albert NM, Allen LA, et al.; American Heart Association Advocacy Coordinating Committee; Council on Arteriosclerosis, Thrombosis and Vascular Biology; Council on Cardiovascular Radiology and Intervention; Council on Clinical Cardiology; Council on Epidemiology and Prevention; Stroke Council. Forecasting the impact of heart failure in the United States: a policy statement from the American Heart Association. Circ Heart Fail 2013; 6:606-19.

5. Jhund PS, Macintyre K, Simpson CR, et al. Long-term trends in first hospitalization for heart failure and subsequent survival between 1986 and 2003: a population study of 5.1 million people. Circulation 2009;119:515-23.

6. Yeung DF, Boom NK, Guo H, et al. Trends in the incidence and outcomes of heart failure in Ontario, Canada: 1997 to 2007. CMA7 2012;184:E765-73.

7. Tu JV, Nardi L, Fang J, et al. National trends in rates of death and hospital admissions related to acute myocardial infarction, heart failure and stroke, 1994-2004. CMA7 2009;180:E118-25.

8. Table 052-0005: Projected population, by projection scenario, age and sex, as of July 1, Canada, provinces and territories. CANSIM (database). Ottawa: Statistics Canada; 2014. Available: www5.statcan.gc.ca/cansim/pick-choisir ?lang=eng\&p2=33\&id=0520005 (accessed 2015 Feb. 28).

9. Table 051-0001: Estimates of population, by age group and sex for July 1, Canada, provinces and territories. CANSIM (database). Ottawa: Statistics Canada; 2014. Available: www5.statcan.gc.ca/cansim/pick-choisir?lang=eng\&p2 =33 \&id=0510001 (accessed 2015 Feb. 28).

10. Surveillance Research Program, Statistical Methodology and Applications Branch, Joinpoint Regression Program Online Help System Version 4.1.1. Bethesda (MD): National Cancer Institute; 2014

11. Pham TM, Fujino Y, Kubo T, et al. Premature mortality due to stroke and trend in stroke mortality in Japan (1980-2005). Eur 7 Public Health 2011; 21:609-12.

12. Kim HJ, Fay MB, Feuer EJ, et al. Permutation tests for joinpoint regression with applications to cancer rates. Stat Med 2000;19:335-51.

13. Patient Cost Estimator. Ottawa: Canadian Institute for Health Information; 2015. Available: www.cihi.ca/pce (accessed 2015 Feb. 26).

14. Cost of a standard hospital stay. Ottawa: Canadian Institute for Health Information; 2015. Available: http://indicatorlibrary.cihi.ca/display/HSPIL/Cost+ of $+a+$ Standard+Hospital+Stay (accessed 2015 Feb. 26).
15. OCCI Costing Analysis Tool. Toronto: Ontario Case Costing Initiative; 2013. Available: https://hsimi.ca/occp/occpreports/ (accessed 2015 Feb. 20).

16. Inflation Calculator. Ottawa: Bank of Canada; 2015. Available: www.bankof canada.ca/rates/related/inflation-calculator/?page_moved=1 (accessed 2015 May 15).

17. Population projections for Canada (2013 to 2063), provinces and territories (2013 to 2038): technical report on, ethodology and assumptions. Ottawa: Statistics Canada; 2014. Available: www.statcan.gc.ca/pub/91-620-x/91-620 -x2014001-eng.htm (accessed 2015 Feb. 28).

18. National health expenditure trends, 1975 to 2014. Ottawa: Canadian Institute for Health Information; 2014.

19. Ezekowitz JA, Kaul P, Bakal JA, et al. Trends in heart failure care: has the incident diagnosis of heart failure shifted from the hospital to the emergency department and outpatient clinics? Eur 7 Heart Fail 2011;13:142-7.

20. Johansen H, Strauss B, Arnold JM, et al. On the rise: the current and projected future burden of congestive heart failure hospitalization in Canada. Can 7 Cardiol 2003;19:430-5.

21. Unroe KT, Greiner MA, Hernandez AF, et al. Resource use in the last 6 months of life among medicare beneficiaries with heart failure, 2000-2007. Arch Intern Med 2011;171:196-203.

22. Kaul P, Reed SD, Hernandez AF, et al. Differences in treatment, outcomes, and quality of life among patients with heart failure in Canada and the United States. 7ACC Heart Fail 2013;1:523-30.

23. Dunlay SM, Shah ND, Shi Q, et al. Lifetime costs of medical care after heart failure diagnosis. Circ Cardiovasc Qual Outcomes 2011;4:68-75.

Affiliations: School of Public Health (Tran, Ohinmaa, Thanh), University of Alberta; Institute of Health Economics (Ohinmaa, Thanh), Edmonton; Department of Medicine (Howlett), University of Calgary, Calgary; Department of Medicine (Ezekowitz, McAlister, Kaul), University of Alberta; Canadian VIGOUR Centre (Ezekowitz, McAlister, Kaul), University of Alberta, Edmonton, Alta.

Contributors: Dat Tran and Padma Kaul conceptualized the study. Arto Ohinmaa and Thanh Nguyen provided input into costing methodology. Dat Tran conducted the analyses and drafted the manuscript. Padma Kaul made significant revisions to the manuscript. All of the authors critically reviewed the manuscript for intellectual content. Dat Tran had full access to the data and serves as the guarantor of the work.

Supplemental information: For reviewer comments and the original submission of this manuscript, please see www.cmajopen.ca/content/4/3 /E365/suppl/DC1 